\title{
Analyzing the Agenda Setting of the Reforming Policy of the Structure of the Central Staff of Medical Universities in Iran in 2013 Using the Model of Multiple Streams of Kingdon
}

\author{
Fatemeh Mohabati ${ }^{1}$, Mohammad Arab ${ }^{1 *}$, Maryam Tajvar ${ }^{1}$, Bahram Mohaghegh², \\ Mohammad Hossein Salarian Zadeh ${ }^{3}$
}

\author{
'Department of Health Management and Economics, School of Public Health, Tehran University of Medical Sciences, Tehran, Iran. \\ 2Department of Public Health, School of Health, Qom University of Medical Sciences, Qom, Iran. \\ ${ }^{3}$ Secretariat of Supreme Council for Health and Food Security, Ministry of Health and Medical Education, Tehran, Iran. \\ ${ }^{*}$ Correspondence to: Mohammad Arab, Iran (E-mail: Arabmoha@tums.ac.ir) \\ (Submitted: 07 December 2020 - Revised version received: 19 January 2021 - Accepted: 06 February 2021 - Published online: 26 October 2021)
}

\begin{abstract}
Objectives: Improving the organizational structure of medical universities and the continuous adaptation to the mission and new functions is an irrefutable necessity. The current article aimed to explain how this improvement was happened in 2019 in Iran medical universities.

Methods: It takes qualitative method with managers and experts from the Ministry of Health and 17 medical universities. Via the Snowball sampling method 57 people were interviewed by using semi-structured in-depth method. MAXQDA 2020 software was used for the content analysis.

Results: The opportunity window was opened for medical universities to reform their organizational structure according the agenda of the Ministry of Health in 11th government. High-level documents and laws related to this subject, in addition to the cooperation of medical universities process owners and the Ministry of Health stakeholders and the formation of specialized working groups lead to formulate organizational structure (policy stream).

Conclusion: Regarding to having a dynamic and flexible structure for meeting environmental needs, Iranian medical universities were modified in 2013 by Ministry of Health policymakers and managers. The Kingdon Multi-Stream Model helps to better understand the content of this policy.

Keywords: Policy analysis, structural reform, Iran
\end{abstract}

\section{Introduction}

Complex systems of health care require the coordination of activities that a proper organizational structure manages under the circumstances and social and political conditions. Universities of Medical Sciences, in addition to educational and research tasks, are responsible for promoting the health of society. Preliminary pathology of the medical universities structure before 2013 indicated problems such as: incompatibility of composition and number of organizational positions of universities with the volume of work, quantitative and qualitative change of new tasks and parallelism in some units tasks. ${ }^{2}$ In addition, the creation of 17 faculties had become a necessity for reforming the medical university's organizational structure. $^{3}$

During the two decades since the last official appraisal the medical university's structure, Iran's population has increased from 55 to 75 million and the number of cities has increased from 229 in the 1990s to 422 in the $2010 \mathrm{~s} ;{ }^{4}$ so, an old organizational structure could not meet the new needs. high-level documents particularly the topics raised in the Fifth Development Plan, as well as existed challenges in the second half of 2013, reviewing the structure of universities was considered as one of the priorities of health system reform and the revised structure was communicated to the universities for implementation from 2016.

Although many researchers have focused on the medical universities organizational structure, however, there have been no organizational structure policy analysis study. ${ }^{6-10}$ Likewise, the lack of such research can be seen in foreign articles. ${ }^{11-14}$
Some researchers have conducted organizational structure studies based on dimensions ${ }^{15-17}$ and the others presented organizational structure models. ${ }^{18-20}$ Using the Kingdon Multiple Streams Model, ${ }^{21}$ the current study aimed to identify the factors affecting the agenda-setting of structural reform policy.

Conducting such studies will evaluate the value of such health policies. In addition, a comprehensive view of the key stakeholders' and policymakers involved in the process of structural reform becomes obvious. Furthermore, current study helps to discover the strengths and weaknesses of the steps taken in this review. It is also expected that the analysis will be able to be used to analyze structural reform programs and policies in other organizations.

\section{Materials and Methods}

\section{Design}

Regarding the aims of the research, to analyze the agendasetting of organizational structure of medical universities, qualitative analysis and case study methods have been usesd. The case study in the current research is the structure and detailed organization of the staff of the country's medical universities. To perform this analysis, the Kingdon Multi-Stream Model was used. ${ }^{21}$

The Multi-Stream Model, proposed by Kingdon in 1984, has been used in numerous studies in the field of health..$^{22-24}$ Using this theory, Kingdon posed questions such as: how issues are considered by the authorities, how the government 
agenda is set, and why time is running out for some ideas. ${ }^{25}$ Accordingly, three streams were identified: 1) the problem stream; this stream signifies the real-world problems and the effects of past government interventions, 2) the policy stream; this stream contains a group of researchers, policymakers, and professionals who analyze problems and suggest options for solving problems, and 3) the political stream, which mostly refers to the activities of influential groups, including elections, managerial changes and electoral policies. ${ }^{26}$ The remarkable thing is that these three streams are independent of each other and each has its own rules and dynamics. ${ }^{27}$ These three streams are connected in certain situations called the window of opportunity (Figure 1), and create major changes in some policies. $^{28}$

After selecting the agenda policy analysis model, the following steps have been taken to conduct research: first, the structural changes background in organizational structure of medical universities have been identified from the high-level documents and resources available in the Ministry of Health, Administrative and Recruitment Affairs Organization, Islamic Consultative Assembly Research Center, reports and relevant news.

Then, the researcher went to research location for gathering information needed to study. After enumerating the factors affecting the subject, their explanation was based on Kingdon's theory.

\section{Participants and Data Collection}

After reviewing the documents, the information has obtained to conduct semi-structured interviews with the knowledgeable people in the field of research.

Based on the typology performed by the Ministry of Health, the selection of 17 universities was done as follows. 1- center of excellence and University of the provincial capital (5 universities), 2-university of the provincial capital, and non-Center of excellence (7 universities) 3- universities those are not central in the province ( 5 universities). The province's central center of excellence universities is mostly large universities across the country, known as mother universities. Non-center of excellence and provincial universities are smaller and shorter-lived than the center of excellence universities. The province's non-centralized universities are universities that were originally affiliated with mother universities but are now independent.

These interviews were done with 57 managers and experts in the universities, the Ministry of Health, the Program and Budget Organization, and the Administrative and Recruitment Affairs Organization using the snowball method. The interviews were conducted in a semi-structured and in-depth manner using open-ended questions. In addition to taking notes, with the permission of the interviewees, the interviews were recorded and then typed at the end. The duration of each interview session was between 34 and 77 minutes. Interviews continued until theoretical saturation. The interviewees were identified by the letter $P$ in this article, and the participants' sentences were marked in Italic font.

\section{Data Analysis}

The interview content was entered in the MAXQDA 2020 software. Then, the text of the interviews was carefully studied several times and coded according to the Kingdon model as separate classes and under the relevant classes. The final position of the text of the interview in the model, was determined by consensus among the authors.

\section{Validity and Reliability}

To ensure the validity and reliability of the interviews in this study, Lincoln and Guba's method was used..$^{29}$ Accordingly, by using the following measures, the researchers tried to increase the validity and reliability of the study: Using the external observer to check the understanding of his possible similarity with the researcher findings dependability; allocating sufficient time to collect data and check findings with some participants, reviewing by the research partner and re-contacting the interviewees to increase the credibility of the findings; using the experts' views in the field of study and conducting

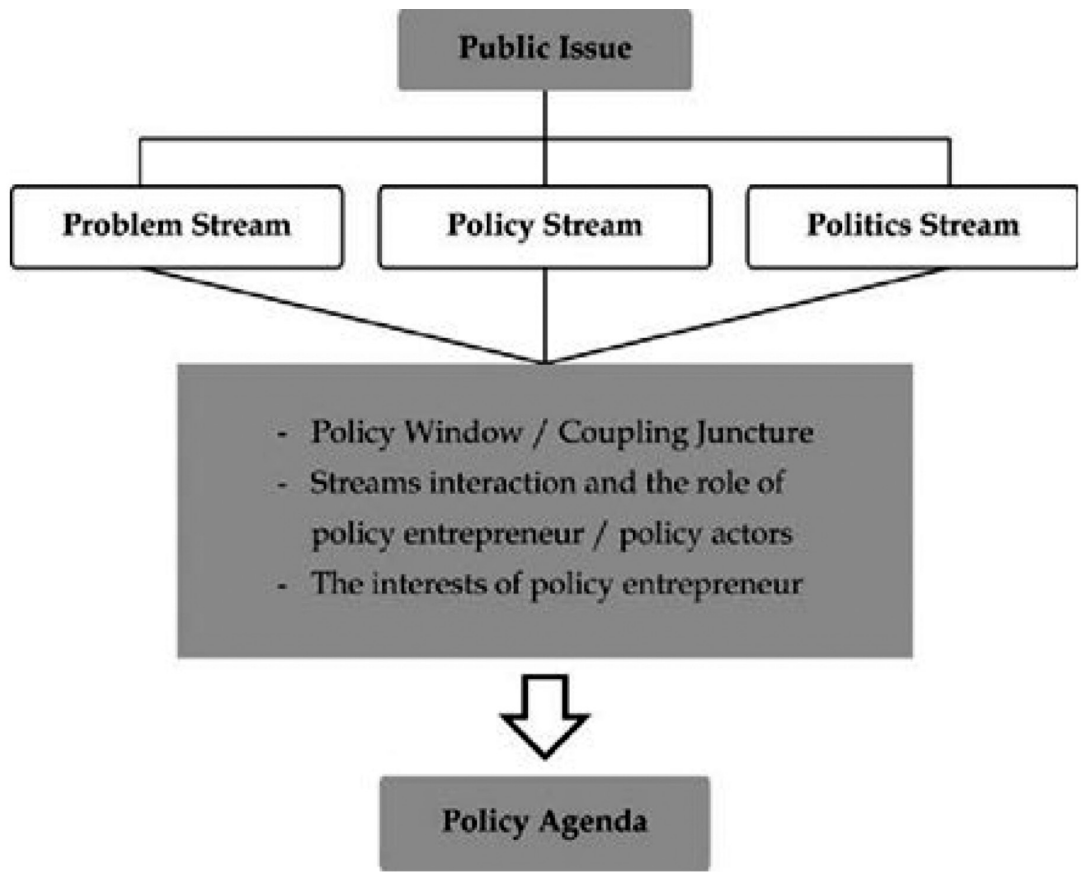

Fig. 1 Kingdon's multiple streams and window of opportunity. 
qualitative studies to findings conformability and the way of themes formation and classes extracted and presenting the results to whom did not participate in the study for transferability findings.

\section{Ethical Consideration}

To observe the ethical points, before collecting the data, the research objectives were explained to the participants and after obtaining informed consent, the interview was recorded. Also, the confidentiality of the participants to participate or exit and the confidentiality of the information, were observed.

\section{Findings}

The findings were obtained in two sections: Demographic findings Table 1, findings from the interviews.

\section{A: Demographic Findings}

Most of the interviewees in this study were male (84.22) and 29.82 of the participants had a master's degree. The highest frequency was in the age group of 41-50 years. Medical universities had the highest number of people interviewed compared to other units (66.67).

\section{B: Findings from the Interview based on Multiple Streams}

Given the framework of Kingdon's multiple streams, ${ }^{25}$ three steams were distinguished: problem streams, the policy stream, and the political stream based on the analysis of the relevant documents.

These three streams and their subcategories are explained from the interviewees' statements and the review of documents. From the analysis of the content of the interviews regarding this reform, 3 categories, and 12 subcategories were extracted as described in Table 2.

\section{Problem Stream}

Due to the need to solve some basic structural problems, the proposal to reform the structure universities of medical universities was suggested.

- Lack of quantitative and qualitative compatibility of university staff units with environmental units

Over the years several quantitative and qualitative ineffective changes had been made in jobs and task which led to a mismatch between universities' functions and missions.
The view of one of the university's interviewees is as follows:

"Over the 20 years, we have increased both our hospitals and our health centers. Consider a person whose staff is the brain and whose environmental units are the hands and legs. During this period, we increased the person's arms and legs, but his brain remained small." (P13)

- Interference and parallel work in the duties of some university staff units

Here is an example of the quotes:

"Well, even with this recent review, there are many parallel units. Our university has identified 50 parallel tasks so far." (P15).

- Separation of several newly established faculties of medical sciences from large universities

One of the interviewees said:

"The establishment of satellite faculties is one of the major structural mistakes in Iran's health system. It makes the staff body fat." (P9)

\begin{tabular}{llcc}
\hline \multicolumn{3}{l}{$\begin{array}{l}\text { Table 1. Frequency distribution and percentage of } \\
\text { demographic characteristics of the participants }\end{array}$} \\
\hline Demographic variable & Frequency & Percent \\
\hline \multirow{2}{*}{ Gender } & Male & 48 & 84.22 \\
& Female & 9 & 15.78 \\
& Under 40 years & 11 & 19.31 \\
Age & 41-50 years & 27 & 47.36 \\
& Over 51 years & 19 & 33.33 \\
& BA & 12 & 21.06 \\
Educational & MA & 17 & 29.82 \\
status & General Ph.D. & 16 & 28.07 \\
& Pharmacist & 3 & 5.26 \\
& Ph.D & 9 & 15.79 \\
\hline \multirow{4}{*}{ Study unit } & University & 38 & 66.67 \\
& Ministry of Health & 11 & 19.30 \\
& Program and Budget & 2 & 3.51 \\
& Organization & & \\
& Administrative and & & 3.51 \\
& Requirement Affairs & 2 & 7.01 \\
& Organization & &
\end{tabular}

\begin{tabular}{|c|c|c|}
\hline Topic & Categories & Sub-categories \\
\hline \multirow{3}{*}{$\begin{array}{l}\text { Structural } \\
\text { reform } \\
\text { agenda } \\
\text { setting }\end{array}$} & $\begin{array}{l}\text { Problem Stream } \\
\text { (health issues) }\end{array}$ & $\begin{array}{l}\text { 1. Quantitative and qualitative change of new responsibilities } \\
\text { 2. Parallel work in the duties of some university staff units } \\
\text { 3. New established medical faculties } \\
\text { 4. Inadequate distribution of manpower between units } \\
\text { 5. Lack of clear evidence in applying structural changes }\end{array}$ \\
\hline & $\begin{array}{l}\text { Policy Stream (Important } \\
\text { events affecting change } \\
\text { within and outside the } \\
\text { health sector) }\end{array}$ & $\begin{array}{l}\text { 1. Existence of historical records and experimental principles and some necessary scientific knowledge } \\
\text { 2. High-level documents, including the Fifth Development Plan } \\
\text { 3. The executive policies of Article } 44 \text { of the Constitution } \\
\text { 4. Cooperation of all process owners and stakeholders }\end{array}$ \\
\hline & $\begin{array}{l}\text { Political Stream (The } \\
\text { political stream of } \\
\text { influential groups) }\end{array}$ & $\begin{array}{l}\text { 1. Political support for the administrative system reforming of universities in development programs } \\
\text { 2. Communicating the comprehensive program of administrative system reform based on the general } \\
\text { policies of the administrative system } \\
\text { 3. Starting the health reform plan as well as the pilot implementation of the family doctor }\end{array}$ \\
\hline
\end{tabular}


- Inadequate distribution of manpower between units in proportion to the level of activity

One of the participants admitted:

"About 50\% of our employees are fit for what they are working in terms of qualifications (specialization, education, and experience), but in some units, such as human and financial resources management, as well as the sub-category of the university presidency, with a large number of religious, and compassionate staff but lack the skills and expertise" (P3).

- The issue of the board of trustees of universities

Many interviewees did not consider universities to have an independent identity despite having a board of trustees.

An interviewee's idea was as follows:

"Structural changes are completely centralized and in the hands of the Ministry." (P22).

This was stated differently in an interview with the Ministry of Health:

"If universities want to be formed via the board of trustees, they will have to pay from the university's budget. Universities expect that with the current payments of staff from the treasury, they will get whatever they want, create whatever levels of management they want." (P23)

- Case opportunism and bargaining for the acquisition of detailed organization by medical universities

Due to the lack of evidence for the implementation of structural changes, top charts were drawn up by the universities. These charts have been approved by the universities board of trustees. Those universities which had more bargaining power had more chance for changing their management levels or units. But, the reform of medical universities organizational structure, reduced the possibility of opportunism

A university interviewee also believed that:

"...... Since our structure has not been revised for a long time and not in accordance with our unit need not, the universities themselves have started to create units that some of these units are not present in the newly announced structure." (P20).

\section{Policy Stream}

Around 2000 and after, a change in attitudes toward the health system in the world were revealed. Also, in Iran, a movement called the reform of the health system began with the financial and technical assistance of the World Bank and the World Health Organization. These reforms took place in all aspects of the health care system, including the structure of service delivery, financing, and trusteeship.

To provide structural support for these reforms, redesigning programs, adopting the laws related to structural reform, and the cooperating all key process owners and stakeholders were considered.

- The records of the subject and empirical foundations and partly scientific

The first steps for universities structure reform taken in (1995) and continued up to (2013). One interviewee believed that:

"Some of the newly established universities think that the structure and organization have come at once, while I have been working in this unit for many years and I know the changes from the beginning to the end." (P12)

- High-level documents including the Fifth Development Plan and permanent rulings
General policies of the health such as the Fifth Development Plan, the document of change in the health system, comprehensive scientific map of the country and executive policies of Article 44 of the Constitution and the compliance of detailed organizations with relevant rules and regulations was as a road map for this reform (2).

One of the interviewees said:

"In the Fifth Development Plan, the university independence issue was addressed in the form of a board of trustees. I don't think it's an exaggeration to say that this law and after that law of permanent rulings as the driving force for universities were for revision" (P17).

- Implementing policies of Article 44 of the Constitution

According to the general policies of Article 44 of the Constitution the Ministry of Health has made efforts to decentralize to save public costs as well as improve the quality of services. one interviewee said:

"Right now, the largest cooperation is government. I think the government should support services that are not attractive to the private sector, such as health services. it was necessary to lay a proper basis in terms of organizational structure and organization in universities to identify and assign non-governmental tasks that can be assigned." (P8)

- Cooperation of all process owners and stakeholders

According to an interviewee's idea from the Ministry of Health:

"We gathered specialist panels from the departments, specialized offices of the headquarters of the relevant ministry, staff departments of universities and colleges, experts and specialists in organizational affairs and organizational structures, owners of specialized processes in staff and operational-executive areas, program planners and policymakers, and we have concluded 160 sessions." (P6).

\section{Political Stream}

As mentioned before, medical universities buckled with various organizational structure problems; so, this issue was considered in the policies and programs.

- Political support for reforming the administrative system of universities in development programs in the form of the board of trustees

The approval of managing the universities via the board of trustees in the Fifth Economic Development Plan Law has been an introduction to the independence of universities in the field of organizational reform.

"I think in the last two decades all political streams has been toward reforming the structure of universities. The Board of Trustees program was mentioned in the fifth program" (P2).

- Announcing a comprehensive program to reform the administrative system

"Politics has not changed. The program of reforming the administrative system was written in 2014. At that time, it had 8 key axes. But now this program has been communicated to government agencies with ten axes." (P7).

- The introduction of the health transformation plan, as well as the pilot implementation of the family physician plan in some provinces, and the need for structural support for this program 
A participant stated:

"Essentially, the health transformation plan was started with Rouhani's government. In Rouhani's government, more attention was paid to reform, and the interest of managers and policymakers in this government is that there are changes and reform in their work record." (P6).

\section{Create a Window of Opportunity to Design and Communicate This Policy}

The problems stream in the field of medical universities organizational structure reform, along with the stream policy that has long been approved by higher laws and documents such as The Fifth Law of Development Program and programs such as the Comprehensive Administrative Reform Program were launched in the country and its latest change concurred with the implementation of the Health System Transformation Plan in the 11th government, and the political stream opened the window of opportunity so that universities can meet their needs by reorganizing their organizations.

\section{Discussion}

The reform of the organizational structure of medical universities is considered as one of the important structural changes in the 2010s. In this regard, one of the common theories of policy change (Kingdon Multiple Stream Theory) was used to explain this policy.

Kingdon's theory enumerates three independent streams and the window of opportunity is created for the greatest changes in a particular policy. Nonetheless, it seems that in the current study, these three streams were not as independent as Kingdon predicts. The stream of structural problems of medical universities and the stream of policy reform of organizational structure had been formed long ago, and these two streams had a mutual effect on each other over time.

Given the content of the high-level laws, especially the General Health Policy Program and the Fifth Development Plan and the Sixth Permanent Development Plan Law, it can be seen that the topic of reforming the universities structure their trustees has been highlighted in legal articles and bills. ${ }^{31}$ The importance of providing a legal framework for the successful formulation and implementation of policies related to health sector reform is also an issue on which previous studies agree. ${ }^{32-34}$

Though the structural problems of universities have always existed, the political stream has made these problems more noticeable. The issue of the effectiveness of political streams on health reform in various ways exists in other countries as well. ${ }^{33-36}$ The two aforementioned streams strengthened the political stream. It seems that, the role of the political stream in opening the window of opportunity for ordering the structural reform is more than the other two streams, since the previous two streams existed for many years, and the political stream led to this structural reform. The experiences of other countries showed that those reforms have taken place in health system, often were created with the appointment of a new Minister of Health. ${ }^{37-38}$

Though, in 2010, with the change of the country's macroconditions and the reforms made in the health system in the framework of the health transformation plan, the revision of the structure was on the agenda. Examples of such policy changes can be seen in some other studies. ${ }^{39-40}$ In the problem stream, Kingdon points out that ideological values and factors play an important role in defining the problem. ${ }^{21}$ For example, proponents of organizational structure revision may have different views on the board of trustees of universities, the independence of universities, university categorization, number of management levels, the scope of supervision, and more.

According to Kingdon, key role players of the structure are people who want to invest their resources, time, energy, and position to achieve a particular outcome or position. ${ }^{21}$ In this case, the key role players of structure review were the minister and some deputies and managers of the ministry, as well as the universities of medical sciences. The position of these individuals, as well as their managerial experience at the university and ministry levels, enabled them to negotiate with other professionals and policymakers to support their ideas.

Though it seems that, the recent review can't address all the issues in this area, it is expected that this process becomes a more dynamic process according to the requirements.

\section{Conclusion}

The critical role of the medical universities the provinces validate the need for the appropriate coordination of their detailed organizational structure with health system. Two decades after the last structural review in 2013, it was possible for universities to organize their manpower in a different structure and organization. Despite the importance of revising the university structure, the review of the available evidence showed the limited and of related studies. These limitations led to understanding the complexity and time-consuming process of reorganizing the structure of medical universities, consider analyzing the policy agenda based on the Kingdon model.

This research analyzed the structure of the policy of reforming the organizational structure of medical universities a qualitative approach by using the opinions of policymakers, managers, and experts of the Ministry of Health and medical universities. Likewise, identifying and reviewing laws, regulations, and documents related to structural reform in the health sector and universities added to the richness of this research.

To achieve this aim, multiple streams involved (problem, political, politics) by using appropriate study methods were analyzed. It seems that with this analysis, a good picture of what is needed to realize the policy of reviewing the structure of universities has been provided. So, it is expected that the results of this analysis will be helpful in future structural revisions of universities. It is suggested that researchers do a study in the field of performance and effectiveness of universities by considering the structural variables to draw the attention of policymakers to feedback on the impact of structural reform policy on university performance.

\section{Acknowledgment}

This study was part of a $\mathrm{PhD}$ thesis supported by Tehran University of Medical Sciences (TUMS); IR.TUMS.SPH. REC.1396.4138.

\section{Conflict of Interest}

The authors declare that they have no competing interests. 


\section{Refrences}

1. Sadaghiani, E., Assessing health care services and hospital standards. 1997: p. 36.

2. Civil Service Reform: A Government Policy, MOHME experience. Salarian Zadeh\& et al. 2018

3. Salarian Zadeh M.h, Yousefian Sh, Mosavi S.M. A way toward Civil Service Reform. The ministry of health and medical education experience. 2017 MOHME publication.

4. Management and planning organization. The law of 5th program of economic, social and cultural development of Islamic Republic of Iran 2011-2015; 2011. (Persian)

5. Zabihi M R, Ebrahimipur H, Arefinia H. The relationship between dimensions of organizational structures and employees' psychological empowerment in Mashhad University of Medical Sciences Quarterly Journal of Nersing Management.2013;2 (1)48-58: http://ijnv.ir/article-1-135-fa.html

6. Jadidi R, Memari F, Anbari Z. The Relationship Between Organizational Structure and Organizational Intelligence in Teaching Hospitals of Arak University of Medical Sciences . J Arak Uni Med Sci. 2013;16 (8):21-31: http://jams.arakmu.ac.ir/article-1-2368-fa.htm

7. Zanganeh Baygi M, Seyedin H, Salehi M, Jafari Sirizi M. Structural and Contextual Dimensions of Iranian Primary Health Care System at Local Level, Iran Red Crescent Med J. 2015 ; 17(1):e17222. doi: 10.5812/ircmj.17222.

8. Zanganeh Baygi M, Seyedin H. Imbalance between Goals and Organizational Structure in Primary Health Care in Iran- a Systematic Review. Iran J Public Health 2013;42(7):665-672.

9. Takian A.H, Rashidian A, Kabir M.J, Expediency and coincidence in reengineering a health system: an interpretive approach to formation of family medicine in Iran, Health Policy and Planning, 2011;26(2):163-173, https://doi.org/10.1093/heapol/czq036

10. Balogun J. The Practice of Organizational Restructuring: From Design to Reality, European Management Journal, 2007; 25(2):81-91, ISSN 0263-2373, https://doi.org/10.1016/j.emj.2007.02.001.

11. Isaak S, McCutcheon D. Organizational Restructuring in Health Care: A Successful Approach, Healthcare Management Forum, 1997; 10(3):34-41, ISSN 0840-4704, https://doi.org/10.1016/S0840-4704(10)60957-X.

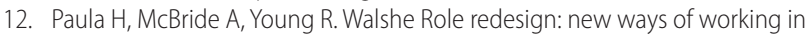
the NHS, Kieran Personnel Review; 2005; 34, 6; Psychology Database pg. 697. DOI 10.1108/00483480510623475

13. Mathisen G.E, Brønnick K, Arntzen K.J, Vestly Bergh L.I, Identifying and managing psychosocial risks during organizational restructuring: It's what you do and how you do it, Safety Science, 2017; 100(Part A):20-29, ISSN 0925-7535, https://doi.org/10.1016/j.ssci.2016.12.007.

14. Maleki M. RTabibi, S.J.A, Nasiripour A. A, Kharazmi E.A structural model for evaluation of the structural complexity dimensions of health and treatment network of Firozabad, Fars Province, Iran, using design structure matrix and quality function deployment techniques. Journal of Research \& Health Social Development \& Health Promotion Research Center. 2014; 4(2): 673-686.

15. Azari H, Yousefi-Amiri M. Assessment and Modeling of the Impact of Management Information Systems on Dimensions of Organizational Structure in the social Security Organization Branches of Qom.Iran. Health Info Management.2016; 13(3): 170-6.

16. Alizadeh S, Maleki M, khodayari zarnaq R, Darzi S, Sadeghi, A. Relationship between Strategy and Organizational Structure: A Comparative Study between Public and Private Hospitals of Tehran. Hospital Journal. 2014 13(1):1-8

17. Zarei R, Afshari M, Jafari M. Providing a Model for organizational structure of Third Generation in the field of Medical Sciences. jha. 2019; 22 (2):99-110: http://jha.iums.ac.ir/article-1-2930-fa.html.

18. Mirkamali S.M, Farhadi Rad, Developing a Fusion Model for Designing the Organizational Structure of Universities. Educational Administration Research, 2013; 5(17): 75-100.
19. Barati Marnani A, Tourani S, Zahiri M. Designing Organizational Structure for Entrepreneurship Centers in Medical Sciences Universities. jha. 2006; 9 (23) : 41-50 : http://jha.iums.ac.ir/article-1-303-fa.html.

20. Kingdon, J., 1984, "Agendas, Alternatives, and Public Policies". Boston: Little, Brown

21. Kiani M M, Tajvar M. Analyzing Normal Delivery Promotion Policy in Health System Reform of Iran: An Application of Kingdon Multiple Streams Model. Health_Based Research. 2018; 3 (4) :367-378 : http://hbrj.kmu.ac.ir/article1-180-fa.html.

22. Behzadifar M, Gorji HA, Rezapour A, Bragazzi NL. The hepatitis C infection in Iran: a policy analysis of agenda-setting using Kingdon's multiple streams framework. Health Res Policy Syst. 2019;17(1):30. doi:10.1186/s12961-0190436-z.

23. Mauti, J., Gautier, L., De Neve, J. et al. Kenya's Health in All Policies strategy: a policy analysis using Kingdon's multiple streams. Health Res Policy Sys 17, 15 (2019). https://doi.org/10.1186/s12961-019-0416-3.

24. Kingdon, J.W., 1995, "Agendas, Alternatives, and Public Policies", (2nd Ed.). New York: Harper Collins.

25. Wee-Ming T,"Multiple Streams Of Change: Explaining The Removal Of Singapore's Casino Ban Using John Kingdon's Agenda-Setting Framework", Asian Journal Of Public Affairs, 2008;2(1);39-53.

26. Kamieniecki, S, "Testing Alternative Theories of Agenda Setting: Forest Policy Change In British Columbia, Canada, Policy Studies Journal, 2000; 28(1):176-189.

27. Oliver, T., "Health Care Market Reform in Congress: The Uncertain Path Form Proposal To Policy", Political Science Quarterly, 106(3): 453-477.

28. Burns N, Grove SK. Understanding nursing research: Building an evidencebased practice: Elsevier Health Sciences; 2010.

29. Akhavan Behbahani A. A review of health policies of Iran in the development plans. Scientific Journal of Medical Organization. 2013; 31(2):105-112. (Persian)

30. Pena CL. Improving Access to Health Care Services through the Expansion of Coverage Program (PEC): The Case of Guatemala. The World Bank, Washington DC, January 2013.

31. Chakraborty S. Philippines' Government Sponsored Health Coverage Program for Poor Households. The World Bank, Washington DC, January 2013.

32. Menon R, Mollahaliloglu S, Postolovska I. Toward Universal Coverage: Turkey's Green Card

33. OnokaCA. Hanson K, Hanefeld J. Towards universal coverage: a policy analysis of the development of the National Health Insurance Scheme in Nigeria. Health Policy and Planning 2014; 1-13

34. MaedaA, Araujo E, Cashin C, Harris J, Ikegami N, R. Reich M. Universal Health Coverage for Inclusive and Sustainable Development A Synthesis of 11 Country Case Studies. The World Bank 1818 H Street NW, Washington.

35. Zahariadis, N., 2007, "the Multiple Streams Framework: Structure, Limitations, Prospects", In P.A Sabatier (Ed), Theories of the Policy Process, pp.7393, Boulder, Co: Westview Press.

36. Savedoff WD, de Ferranti D, Smith AL, Fan V. Political and economic aspects of the transition to universal health coverage. The Lancet. 2012;380(9845):924-32

37. Yousefvand, Mani \& Olyaeemanesh, Alireza \& Arab, Mohammad \& Jaafaripooyan, Ebrahim. (2018). The behavior of basic health insurance Organizations after the implementation of Relative Value of Health Services book in Iran: A qualitative study. Medical Journal of the Islamic Republic of Iran. 32. 110-110. 10.14196/mjiri.32.110

38. Efat Mohamadi, Policy analysis, problem identification and proposing policy options for Health Insurance Benefit Package in Iran Health System a dissertation for PHD degree. 2017. Tehran University of Medical Sciences. Register 240/2223. 